với các công tác khác. Một trong lý do công tác theo dõi còn hạn chế một phần có thể do nguồn nhân lực chưa đủ đáp ứng cho vai trò này. Mặc dù đa số nhân thức được sự cần thiết của các tiêu chí đánh giá, việc triển khai thực hiện các tiêu chí này lại không đáp ứng được kỳ vọng đạt ra. Trong đó, chỉ có 1 trên 7 tiêu chí được trền $70 \%$ cơ sở thực hiện, ba tiêu chí về tỷ lệ chuyển kháng sinh tiểm sang uống (30\%), DOT (40\%) và $\mathrm{DDD}(49 \%)$ được nhìn nhận là khó thực hiện. Việc tự động hóa phân tích một số chỉ số thường quy như $A B C, A T C$ còn ít (dưới $5 \%$ ). Do đó, cần đầy manh ứng dụng CNTT hỗ trợ phân tích các tiêu chí từ đó giảm tải hoạt động cho nhân viên y tế và giúp đưa ra các quyết định điều trị hiệu quả hơn.

\section{KẾT LUẬN}

Thông qua việc khảo sát tình hình triển khai chương trình QLKS tại các cơ sở nhận thây rằng nguồn lực là vô cùng quan trọng. Các cơ sở cần đẩy mạnh ngân sách, cơ sở vật chất hơn nữa, đồng thời cần nguồn nhân lực không chỉ đủ vế số lượng mà còn phải cả về chất lượng tức là phải nắm bắt kịp thời, vận dụng được các chỉ số trong công tác thường quy. Điều này thì đòi hỏi công tác đào tạo nhân lực cần được chú trọng hơn nữa. Bên cạnh đó việc bổ sung thêm một số tiêu chí phù hợp với quy mô, thực trạng của cơ sở và có hướng dẫn cụ thể trong tính toán các chỉ số đo lượng, cách thu thập dữ liệu hiệu quả. Đồng thời cần đẩy mạnh áp dụng công nghệ thông tin vào quá trình thực hiện hơn nữa, sử dụng phần mềm tự động hóa để tiết kiệm thời gian, chi phí và chính xác hơn.

\section{Lờ' CẢM ƠN}

Nghiên cứu này được tài trợ bởi Sở Khoa Học và Công nghệ Thành phố Hồ Chí Minh (DOST HCMC) cho TS. Nguyễn Thị Hải Yến và ThS Huỳnh Phương Thảo tại Quyết định số 51/QĐ-SKHCN

\section{TÀI LIẸU THAM KHẢO}

1. N. Van Kinh, "Situation Analysis: Antibiotic Use and Resistance in Vietnam."

2. T.-H.-Y. Nguyen et al., "Implementation status of antimicrobial stewardship programs in hospitals: A quantitative analysis study in $\mathrm{Ho}$ Chi Minh city, Vietnam," Medpharmres, vol. 4, no. 2, pp. 34-39, 2020, doi: https://doi.org/ 10.32895/ UMP.MPR.4.2.5.

3. Chính phủ, "Nghị định 16/2015/NĐ-CP quy định cơ chế tự chủ của đơn vị sự nghiêp công lập," 2015.

4. Chính phủ, Nghị định số 85/2015/NĐ-CP về cơ chế hoat động, cớ chế tài chính đối với các đơn vị sự nghiệp y tế công lập và giá dịch vụ khám bệnh, chữa bểnh của các cở sở khám bệnh, chữa bệnh công lập. 2012.

5. M. Mushtaque, F. Khalid, A. A. Ishaqui, R. Masood, M. B. Maqsood, and I. N. Muhammad, "Hospital Antibiotic Stewardship Programs - Qualitative analysis of numerous hospitals in a developing country," Infect. Prev. Pract., vol. 1, no. 3, p. 100025, 2019, doi: https://doi.org/10.1016/j.infpip.2019.100025.

\title{
KHẢO SÁT TÌNH TRANG THIẾU VITAMIN D Ở NGƯỜI BỆNH VIỀM KHỚP - CộT SỐNG
}

\section{TÓM TẮT.}

Mục tiêu: Khảo sát tình trạng thiếu vitamin $D$ ở người bệnh viêm khớp - cột sống. Đối tượng và phương pháp nghiên cứu: nghiên cứu mổ tả cắt ngang trên 67 người bệnh được chẩn đoán viêm khớp - cột sống theo tiêu chuẩn của ASAS tại khoa Cơ Xưởng Khởp bệnh viện Bạch Mai. Thiếu hụt vitamin $D$ được xác định khi nồng độ 25(OH)D3 huyết thanh < $30 \mathrm{ng} / \mathrm{ml}$. Kết quả: Nồng độ vitamin $\mathrm{D}$ trung bình của nhóm bệnh nhân nghiên cứu là $26,1 \pm 6,72 \mathrm{ng} / \mathrm{ml}$, tỉ lệ bệnh nhân có thiêu hụt nồng độ vitamin $D$ là $64,2 \%$.

\footnotetext{
${ }^{1}$ Trường Đại học Y Dược Thái Bình

Bênh viên Đa khoa Tầm Anh

Chịu trách nhiệm chính: Ngô thị Hoài

Email: ngohoaiytb@gmail.com

Ngày nhận bài: 8.7.2021

Ngày phản biện khoa học: 3.9.2021

Ngày duyệt băi: 10.9.2021
}

\section{Ngô Thị Hoài ${ }^{1}$ Đặng Hồng Hoa ${ }^{2}$, Lê Minh Hiếu ${ }^{1}$}

Kết luận: Tình trạng thiếu vitamin D khá phổ biến ở bệnh nhân viêm khớp - cột sống.

Tư khóa: Vitamin D, viêm khớp - cột sống

\section{SUMMARY \\ SERVEY ON VITAMIN D DEFICIENCY IN SPONDYLOARTHRITIS PATIENTS}

Aims: determine the prevalence of vitamin D deficiency among patient spondyloarthritis. Methods: a cross study was conducted with 67 patients with spondyloarthritis at Department of Rheumatologie, Bach Mai hospital and E hospital. Vitamin D deficiency was defined as serum Vitamin $D<30 \mathrm{ng} / \mathrm{ml}$. Results: The average serum Vitamin $D$ is $26,1 \pm 6,72 \mathrm{ng} / \mathrm{ml}$, the prevalence of vitamin $\mathrm{D}$ deficiency is $64,2 \%$. Conclusion: Vitamin $D$ deficiency in patient spondyloarthritis is popular.

Keywords: Vitamin D; spondyloarthritis 


\section{I. ĐẶT VẤN ĐỀ}

Các viêm khớp liên quan đến viêm côt sống (Viêm khớp - cột sống - Spondyloarthritis) là nhóm bệnh phức tạp, đan xen và chồng chéo. Bệnh hay khởi phát ở người trẻ, đặc biệt là nam giới trong độ tuổi thanh thiếu niên, trển những cơ địa đặc biệt, thường có mang gen HLA- B27. Viêm đốt sống là một loại viêm khớp tấn công vào cột sống (triệu chứng thường gặp nhất). Ở một số người khác, bệnh có thể khởi phát viêm ở các khớp lớn (khớp háng) hoặc các khớp ngoai vi. Ngoài ra, bệnh có thể liên quan đến các biểu hiện ở da, ruột và mắt. Bệnh lý viêm khớp - cột sống thuộc nhóm bệnh tự miển dịch, tiến triển kéo dài, có nhiều đợt viêm cấp tính. Gần đây, đã có những nghiên cứu cho thây tình trạng tăng nồng độ TNF- $a$ ở những người bệnh viêm khớp - cột sổng làm giảm hoạt động của Enzyme 24hydroxylase ở thận, đồng thời sự khiếm khuyết của các thụ thể hấp thu vitamin $D$ ở đường ruột cũng được quan sát thấy ở người bệnh nhân này, do đó tình trạng thiếu hụt thiếu vitamin $D$ ở nhóm người bệnh này ngày càng trở nên phổ biến ${ }^{1}$.

Vitamin $\mathrm{D}$ là một tiền hormon tan trong dầu có vai trò quan trọng trong điêuu hòa chuyển hóa canxi và cân bằng nội môi ${ }^{2}$. Gần đây đã có nhiều bằng chứng chỉ ra vitamin $\mathrm{D}$ có liên quan đến điều hòa hoạt động của hệ miễn dịch cũng như điều chỉnh các phản ứng viêmm ${ }^{2,3}$. Trên thế giới đã có môt số nghiên cứu về tình trang thiếu hụt vitamin $\mathrm{D}$ ở những người mắc bệnh viêm khớp cột sống ${ }^{4}$. Tại Việt Nam, hiện chưa có công bố nào về đề tài này, vì vậy chúng tôi tiến hành thực hiện nghiên cứu này với mục tiêu: Khảo sát tình trạng thiếu vitamin $D$ ở người bênh viêm khớp - cột sống.

\section{II. ĐỐI TƯỢNG VÀ PHƯƠNG PHÁP NGHIÊN CỨU}

Thiết kế nghiên cứu: nghiên cứu mô tả cắt ngang một chùm ca bệnh, chọn mấu thuận tiện.

Đối tượng nghiên cứu: Gồm 67 người bệnh được chẩn đoán viêm khớp - cột sống theo tiêu chuẩn của ASAS-2011, điều trị nội trú tại khoa Nội Cơ Xương Khớp thuộc Bệnh viện Bạch Mai từ tháng 9/2020 đến tháng 7/2021, đồng ý tham gia nghiên cứu.

Tiêu chuẩn loại trư. Những người bệnh viêm khớp - cột sống có các bệnh đồng mắc gây ảnh hưởng đển hấp thu và chuyển hóa vitamin D: suy thận mạn, ung thư giáp, rối loạn hấp thu hoặc đang sử dụng các thuốc ảnh hưởng đến chuyển hóa và hấp thu vitamin $\mathrm{D}$ : Rifampicin, Carbamazepine, Cimetidine... hoặc đang được bổ xung canxi - vitamin D.
Phương pháp thu thập số liệu: Thông tin cá nhân của người bệnh được thu thập dựa trên bộ câu hỏi có sẵn. Hỏi bệnh và khám lâm sàng. Xét nghiệm nồng độ vitamin $D$ trong mẫu huyết thanh được thực hiện tại khoa Hóa sinh, Bệnh viện Bạch Mai, trên máy phân tích miễn dịch Coban E 6000 của hãng Roche. Nồng độ vitamin $\mathrm{D}$ được đánh giá bằng giá trị nồng độ $25(\mathrm{OH}) \mathrm{D} 3$ huyết thanh và được chia thành 3 mức độ: thiếu nặng: $\leq 20 \mathrm{ng} / \mathrm{ml}$, thiếu vừa: $21-29 \mathrm{ng} / \mathrm{ml}$ và bình thương: $\geq 30$ theo phân loai của Holick (2007) ${ }^{5}$

Phân tích số liệu: Số liệu được tổng hợp và xử lý trên phần mềm SPSS 16.0. Các thuật toán sử dụng: phân tích giá trị trung bình (mean), độ lệch chuẩn (standard deviation).

Đạo đức nghiên cứu. Đề tài đã được Hội đồng đạo đức trường Đại học Y Hà Nội thông qua. Thông tin thu thập từ nghiên cứu được mã hóa, định danh và giữ kín. Các kết quả được phân tích tổng hợp, không công bố thông tin cá nhân và chỉ phân tích phục vụ cho mục tiêu nghiên cứu.

\section{KẾT QUẢ NGHIÊN CỨU}

Trong số 67 đối tượng nghiên cứu được chẩn đoán viêm khớp - cột sống theo tiêu chuẩn ASAS 2011 , tỷ lệ nam chiếm $83,6 \%$, tuổi trung bình là $32,5 \pm 13,6$ năm, trong đó nhóm tuổi có tỉ lệ cao nhất là nhóm 16 đến 30 tuổi chiếm tỉ lệ $53,7 \%$. Tỉ lệ nam/nữ khoảng 5/1 (56/11). Chỉ số khối cơ thể (BMI) trung bình là 21,38 $\pm 2,56$, phân lớn đối tượng nghiên cứu có BMI bình thường $(71,64 \%)$.

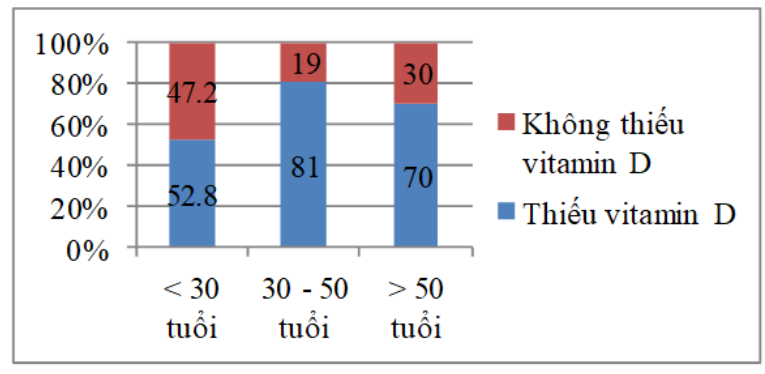

Biểu đồ 1. Tình trạng vitamin $D$ theo độ tuổi của đôî tượng nghiên cứu $(n=67)$

Nhận xét: Tỉ lệ đối tượng nghiên cứu có thiếu vitamin $\mathrm{D}$ ở độ tuổi $<30,30-50$, và $>50$ tuổi lần lượt là $52,8 \%, 81 \%$ và $70 \%$. Không có sự khác biệt về tỉ lệ thiếu vitamin $D$ giữa các độ tuổi.

Bảng 1. Đặc điểm chung về nồng độ Vitamin D của nhóm nghiên cứu

\begin{tabular}{|c|c|c|}
\hline $\begin{array}{c}\text { Phân tâng tình trạng } \\
\text { vitamin D }\end{array}$ & $\mathbf{n = ~ 6 7}$ & $\mathbf{\%}$ \\
\hline Bình thường & 24 & 35,8 \\
\hline
\end{tabular}




\begin{tabular}{|c|c|c|}
\hline Thiếu vưa & 24 & 35,8 \\
\hline Thiếu nặng & 19 & 28,4 \\
\hline $\bar{x} \pm$ SD & \multicolumn{2}{|c|}{$26,10 \pm 6,72 \mathrm{ng} / \mathrm{ml}$} \\
\hline
\end{tabular}

Nhânn xét: Nồng độ vitamin D của các ĐTNC là $26,10 \pm 6,72 \mathrm{ng} / \mathrm{ml}$, tỉ lệ thiếu hụt là $64,2 \%$, trong đó tỉ lệ thiếu nặng là $28,4 \%$.

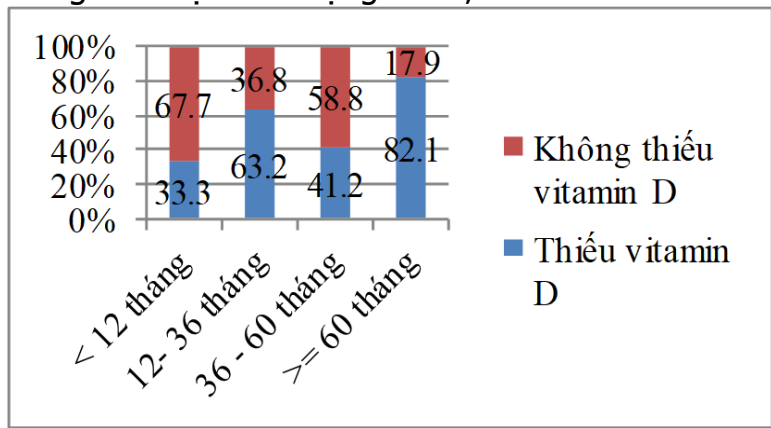

Biểu đồ 2. Tình trạng vitamin $D$ theo thời gian mắc bệnh của đối tượng nghiên cứu $(n=67)$

Nhận xét: Tỉ lệ đối tượng nghiên cứu có thiếu vitamin $D$ thấp nhất ở nhóm có thời gian mắc bệnh < 12 tháng $(33,3 \%)$, cao nhất ở mhóm có thời gian mắc bệnh $\geq 60$ tháng $(82,1 \%)$, sự khác biệt có ý nghĩa thống kê với $p$ $=0,019<0,05$.

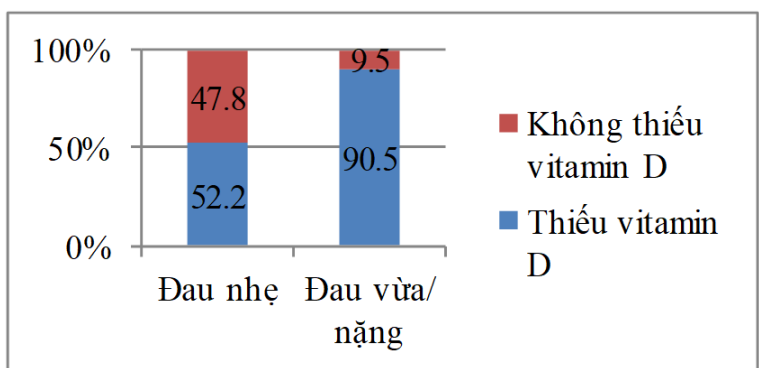

Biểu đồ 3. Tình trạng vitamin $D$ theo mức độ đau (VAS) của đối tượng nghiên cứu $(n=67)$

Nhận xét: Tỉ lê đối tượng nghiên cứu có thiếu vitamin $D$ ở nhóm có mức độ đau nhe là $52,2 \%$ thấp hơn có ý nghĩa thống kê với $p=$ $0,002<0,05$ so với tỉ lệ ĐTNC có thiếu vitamin $D$ ở nhóm có mức độ đau vừa/ nặng $(90,5 \%)$.

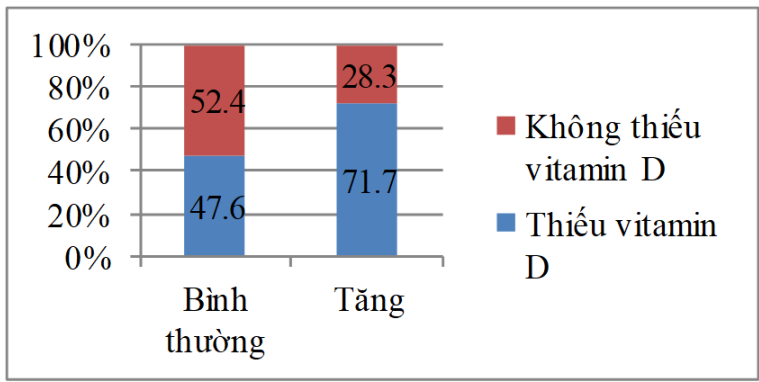

Biểu đồ 4. Tình trạng thiếu vitamin $D$ theo CRP của đối tượng nghiên cứu $(n=67)$
Nhận xét: Tỉ lệ đối tượng nghiên cứu có thiếu vitamin $D$ ở nhóm có CRP bình thường là $47,6 \%$ thấp hơn so với tỉ lệ đối tượng nghiên cứu có thiếu vitamin $\mathrm{D}$ ở nhóm có CRP tăng (71,7\%), sự khác biệt có ý nghĩa thống kê với $p$ $=0,046<0,05$.

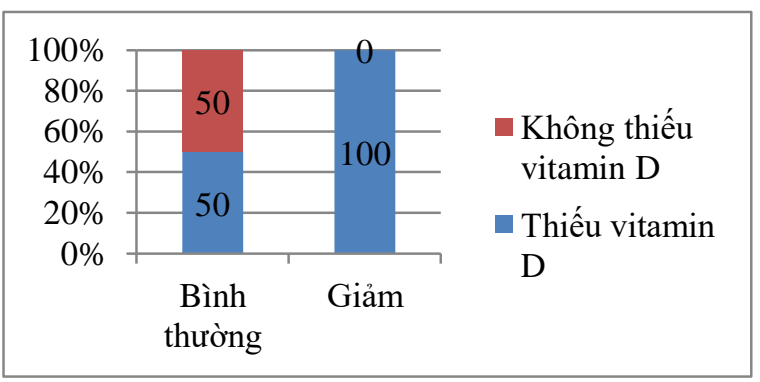

Biểu đồ 5. Tình trạng vitamin D canxi toàn phần của đối tượng nghiên cứu $(n=67)$

Nhâan xét: Tỉ lệ đối tượng nghiên cứu có thiếu Vitamin $\mathrm{D}$ ở nhóm có canxi toàn phần bình thường là $50 \%$ thấp hơn tỉ lệ đối tượng nghiên cứu có thiếu Vitamin $\mathrm{D}$ ở nhóm có canxi toàn phần giảm $(100 \%)$. Sự khác biệt này có ý nghĩa thống kê $(p=0,0001<0,05)$

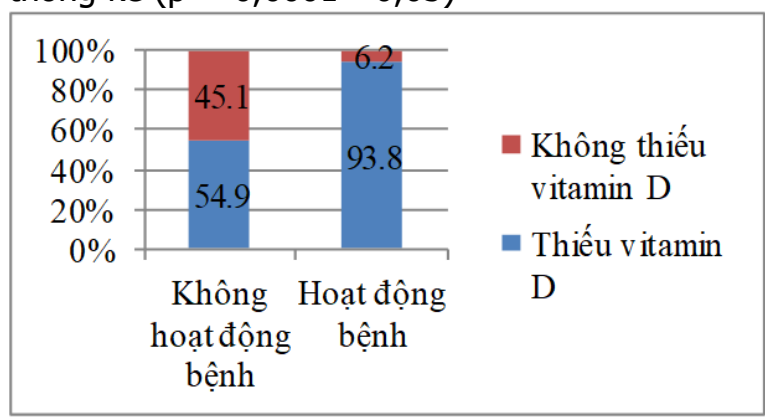

Biểu đồ 6. Tình trạng vitamin $D$ theo chi số BASDAI của các DTNC $(n=67)$

Nhận xét: Tỉ lệ đối tượng nghiên cứu có thiếu vitamin $D$ ở nhóm không có hoạt động bệnh là $54,9 \%$ thấp hơn có ý nghĩa thống kề (p $=0,005<0,05)$ so với tî lệ đối tượng nghiên cứu có thiếu vitamin $\mathrm{D}$ ở nhóm có hoạt động bệnh (93,8\%).

\section{BÀN LUÂN}

Kết quả nghiên cứu của chúng tôi trên 67 đối tượng nghiên cứu được chẩn đoán viêm khớp cột sống theo tiêu chuẩn ASAS 2011 cho thấy tuổi trung bình của nhóm nghiên cứu là $32,5 \pm 13,6$ năm, trong đó nhóm tuổi có tỉ lệ cao nhất là nhóm 16 đến 30 tuổi chiếm tỉ lệ $53,7 \%$. Tỉ lệ nam/nữ khoảng $5 / 1$. Kết quả này cho thấy bệnh lý viêm khớp - cột sống phần lớn gặp ở nam giới trẻ tuổi, là những người đang trong độ tuổi lao động. Do vậy, bệnh ảnh hưởng nhiều đến thể 
chất cũng như đời sống kinh tế của người bênh và xã hội. Độ lệch (mức độ dao động) về tuổi trong nghiển cứu này tương đối cao phù hợp với tính chất diễn biến mạn tính của bệnh. Kểt quả này của chúng tôi cũng phù hợp với kết quả của các nghiên cứu đã công bố trước đây ${ }^{1,6}$.

Gần đây, nhiều nghiên cứu đã chứng minh nồng độ vitamin $D$ trong cơ thể có liên quan đến điều hòa hoat đông của hê thống miễn dich cả trên miễn dịch tự nhiên và miễn dịch thu được cũng như điều chỉnh các phản ứng viêm. Trển thế giới có nhiều nghiên cứu về tình trạng thiếu vitamin $\mathrm{D}$, nhiều tác giả cho rằng thiếu vitamin $\mathrm{D}$ làm tăng tình trạng hoạt động bệnh, ngược lại sự suy giảm chức năng, cấu trúc có thể làm trầm trọng thêm tình trang thiếu vitamin $D$ do giảm tiếp xúc với ánh nắng mặt trời. Theo quan điểm này tình trạng thiếu vitamin $D$ có thể là hậu quả của bệnh viêm khớp - cột sống hơn là nguyên nhân của nó ${ }^{3}$. Bekir Dumus và cộng sự cho rằng nguyên nhân gây giảm nồng độ vitamin $D$ ở bệnh nhân viêm cột sống là do giảm tiếp xúc với ánh nắng mặt trời, do các bệnh lí ở ruột, làm giảm các thụ thể hấp thu vitamin $D$, và đặc biệt do tình trạng tăng cao của TNF a gây ức chế hoạt động của men 1 alpha hydroxylase làm giảm quá trình chuyển hóa của vitamin $D$ tại thận do vậy làm giảm hoạt tính sinh học của vitamin $D^{1}$. Trong nghiên cứu của chúng tôi, nồng độ Vitamin $D$ trung bình của nhóm nghiên cứu là $26,1 \pm 6,72 \mathrm{ng} / \mathrm{ml}$, tỉ lệ đối tượng nghiên cứu có thiếu - hụt (giảm vửa đến giảm nặng) nồng độ vitamin $D$ là $64,2 \%$ (Bảng 1 ). Kết quả nghiên cứu này tương tự với nghiên cứu của Zofia Guta và cộng sự công bố năm 2018 khi nghiên cứu trên 40 bênh nhân viêm cột sống thể trục và 23 bênh nhân viêm khớp cột sống thể ngoại vi tại Ba Lan cho thấy nồng độ trung bình của vitamin $D$ trong huyết thanh là $24,9 \pm 12,49 \mathrm{ng} / \mathrm{ml}, 74,6 \%$ bênh nhân có vitamin $D$ dưới ngưỡng khuyến cáo $(<30 \mathrm{ng} / \mathrm{ml})^{7}$.

Khi khảo sát tình trang vitamin $\mathrm{D}$ theo tuổi (biểu đồ 1 ) chúng tôi thấy tỉ lệ ĐTNC có thiếu vitamin $D$ ở độ tuổi < 30 thấp nhất $(52,8 \%)$, tỉ lệ này tăng ở độ tuổi $>50(70 \%)$ và cao nhất ở độ tuổi 30 - 50 cao nhất ( $81 \%)$. Không có sự khác biệt về tỉ lệ thiếu vitamin $D$ giữa các độ tuổi $(p=$ $0,093>0,05$ ). Nồng độ vitamin $D$ trong huyết thanh trung bình cao nhất ở độ tuổi $<30$ $(28,45 \pm 6,34)$, thấp nhất ở độ tuổi $30-50$ $(22,89 \pm 6,08)$. Sự khác biệt nà̀y có ý nghĩa thống kê với $\mathrm{p}<0,05$. Kết quả nghiên cứu của chúng tôi không tương đồng với kết quả nghiên cứu của Hồ Phạm Thục Lan công bố năm 2010 trên 205 nam và 423 nữ giới khỏe manh tuổi từ 18 đến 87 thây có sự khác biệt đáng kể về tỉ lệ thiếu hụt vitamin $D$ giữa các độ tuổi, ở nữ giới tî lệ thiếu hut vitamin $\mathrm{D}$ cao nhất ở những người có độ tuổi trên $60(56 \%)$ và dưới $30(50 \%)$, ở độ tuổi 30 - 60 tỉ lệ này là $40 \%$, tương tự ở nam giới tỉ lệ thiếu hụt vitamin $\mathrm{D}$ cao nhất ở những người có độ tuổi trên 60 (23\%), dưới 30 (33\%), ở độ tuổi 30 - 60 tỉ lệ này chỉ là $10 \%{ }^{8}$. Sự không tương đồng giữa 2 kết quả nghiên cứu có thể do trong nghiên cứu của Hồ Phạm Thục Lan, đối tượng nghiên cứu là người khỏe mạnh, những người trẻ tuổi có xu hướng thích làn da trắng nên thường tránh tiếp xúc với ánh nắng mặt trời. Trong nghiên cứu này có tới $54 \%$ phụ nữ trẻ tuổi và $36 \%$ nam giới trẻ tuổi tham gia nghiên cứu và có thời gian tiếp xúc với ánh nắng mặt trời ít hơn 10h/tuần. Ở nghiên cứu của chúng tôi, các đối tượng nghiên cứu là bệnh nhân viêm khớp - cột sống, tình trạng thiếu vitamin $D$ không chỉ bị ảnh hưởng bởi các yếu tố tuổi, thời gian tiếp xúc với nắng mă̆t trời mà quan trọng hơn, thiếu vitamin $D$ có thể là yếu tố khởi phát hoặc là hậu quả của tình trang viêm mạn tính và tiến triển của bệnh.

Thời gian mắc bênh của người bị mắc viêm khớp - cột sống càng dài thì nguy cơ hạn chế vận động của người bệnh càng cao đồng thời sự ức chể hoạt động của Enzyme 24- hydroxylase ở thân có nguy cơ tăng lên ${ }^{1}$, điều này được thể hiện qua kết quả nghiên cứu của chúng tôi ở biểu đồ 2. Kết quả cho thấy tî̉ lệ đối tượng nghiên cứu có thiếu vitamin $D$ thấp nhất ở nhóm có thời gian mắc bênh $<12$ tháng $(33,3 \%)$, cao nhất ở nhóm có thời gian mắc bệnh $\geq 60$ tháng $(82,1 \%)$, sự khác biệt có ý nghĩa thống kê với $p$ $=0,019<0,05$. Kolahi và cộng sự công bố năm 2019 khi nghiên cứu trên 86 bệnh nhân viêm khớp- cột sống tại Iran thây thời gian mắc bệnh trung vị 60 tháng (dao động từ 6-490 tháng, Zhao và công công bố năm 2017 khi nghiên cứu trên 235 bênh nhân axialSpA tại Anh thây thời gian mắc bệnh trung bình là 4,3 năm (dao dộng từ 0,8-14,9 năm).

Vitamin $D$ có vai trò quan trong trong điêu hòa cân bằng canxi nôi môi, kích thích sự hấp thu canxi, phosphate ở đường tiêu hóa và thận. Khi khảo sát tình trang vitamin $\mathrm{D}$ theo canxi máu (biểu đồ 3) cho thấy tỉ lệ đối tượng nghiên cứu có thiếu vitamin $D$ ở nhóm có canxi toàn phần bình thường là $50 \%$ thấp hơn tỉ lệ đối tượng nghiên cứu có thiếu vitamin $\mathrm{D}$ ở nhóm có canxi toàn phần giảm (100\%). Tỉ lệ đối tượng nghiên cứu có thiếu vitamin $\mathrm{D}$ ở nhóm có canxi ion bình thường là $45 \%$ thấp hơn tỉ lệ ĐTNC có thiếu vitamin D ở 
nhóm có canxi ion giảm $(92,6 \%)$, sự khác biệt này có ý nghĩa thống kê $(p=0,0001<0,05)$.

Tình trạng hoạt động bệnh và mức độ hoạt động bệnh được thể hiện qua thang điểm đánh giá mức độ đau VAS, chỉ số đánh giá viêm (CRP) và chỉ số BASDAI. Kết quả nghiên cứu của chúng tôi thể hiện ở biểu đồ 4 , biểu đồ 5 và biểu đồ 6 cho thấy tỉ lệ thiếu vitamin $D$ ở nhóm đối tượng nghiên cứu có mức độ đau vừa hoặc nặng (90,5\%) cao hơn so với nhóm đối tượng nghiên cứu có mức độ đau nhẹ $(52,2 \%)$, ở nhóm có chỉ số CRP tăng tỉ lệ thiếu vitamin $D$ là $71,7 \%$ cũng cao hơn nhóm có chỉ số CRP bình thường (47,6\%). Tương tự như vậy, tỷ lệ thiếu vitamin D ở nhóm đối tượng nghiên cứu có chỉ số BASDAI thấp (không hoạt động bệnh) là 54,9\% thấp hơn so với tỉ lệ thiểu vitamin $D$ ở nhóm có chỉ số BASDAI cao (đang hoạt dộng bệnh) (93,8\%). Có sự liên quan giữa tình trạng thiếu vitamin $D$ với mức độ đau (VAS), chỉ số CRP và chỉ số BASDAI $(p<0,05)$. Kết quả nghiên cứu này tương tự với nghiên cứu của ZHAO và cộng sự công bố năm 2017 khi nghiên cứu trên 235 bệnh nhân viêm khớp - cột sống thể trục tại Anh cho thấy sự thiếu hụt vitamin $D$ có liên quan đến mức độ đau (VAS) (OR=1,21,95\%, CI: 1,07-1,38), chỉ số CRP (OR= 1,02, CI 95\%: 1,01-1,04,) chỉ số hoạt động bệnh BASDAI (OR=1,23, 95\% CI: 1,06 - 1,41).

\section{KẾT LUẬN}

Tình trạng thiếu hụt vitamin $D$ gặp khá phổ biến ở bệnh nhân viêm khớp - cột sống. Sự thiếu hụt này càng tăng lên khi người bệnh có thời gian mắc bệnh kéo dài hoặc có các dấu hiệu bệnh đang hoạt động mạnh như mức độ đau vừa hoặc nặng (tăng điểm VAS), các chỉ số CRP và BASDAI tăng cao. Do đó, xét nghiệm định lượng nồng độ vitamin $D$ là cần thiết, giúp cho các thày thuốc lâm sàng có thể bổ sung vitamin D sớm cho các đối tượng này.

\section{TÀI LIÊUU THAM KHẢO}

1. Durmus B, Altay Z, Baysal O, Ersoy Y. Does vitamin D affect disease severity in patients with ankylosing spondylitis? Chin Med J (Engl). 2012;125(14):2511-2515.

2. Vitamin $D$ treatment for connective tissue diseases: hope beyond the hype? | Rheumatology | Oxford Academic. Accessed May 22, 2020. https://academic.oup.com/rheumatology/article/56 /2/178/2631547

3. Crotti $C$, Becciolini $A$, Biggioggero $M$, Favalli EG. Vitamin D and Spondyloarthritis: Review of the Literature. Open Rheumatol J. 2018;12(1). doi:10.2174/1874312901812010214

4. Fernandes $\mathbf{S}$, Etcheto $\mathbf{A}$. Vitamin $D$ status in spondyloarthritis: results of the ASAS-COMOSPA international study. Clin Exp Rheumatol. Published online 2018:5.

5. Vitamin-D-deficiency.pdf. Accessed September 4, 2021. http://www.beauty-review.nl/wp-content/ uploads/2015/04/Vitamin-D-deficiency.pdf

6. Ismail M F, El-Mansoury TM, Abd El-Karim AH, et al. Vitamin D status in ankylosing spondylitis patients: Relation to bone health, disease activity, functional status, spine mobility and enthesitis. Egypt Rheumatol. 2020;42(4):291295. doi:10.1016/j.ejr.2020.08.005

7. Guła $Z$, Kopczyńska A, Hańska $K$, et al. Vitamin D serum concentration is not related to the activity of spondyloarthritis - preliminary study. Reumatologia. 2018;56(6):388-391. doi:10.5114/ reum.2018.80717

8. Ho-Pham L, Nguyen $\mathbf{N}$, Lai $T$, Eisman J, Nguyen $\mathbf{T}$. Vitamin $\mathrm{D}$ status and parathyroid hormone in a urban population in Vietnam. Osteoporos Int J Establ Result Coop Eur Found Osteoporos Natl Osteoporos Found USA. 2010;22:241-248. doi:10.1007/s00198-010-1207-4

\section{ĐĂC ĐIỂM LÂM SÀNG VÀ TÌNH TRANG DI CĂN HẠCH CỦA VI UNG THƯ TUYẾN GIÁP THỂ NHÚ}

\section{TÓM TẮT.}

Mục tiêu: đánh giá đặc điểm lâm sàng và tình trạng di căn hạch của vi ung thư tuyến giáp thể nhú tại bệnh viện Đại học Y Hà Nội. Đối tượng và

${ }^{1}$ Bệnh viện Đại học Y Hà Nội

Chịu trách nhiệm chính: Nguyễn Xuân Hậu

Email: nguyenxuanhau@hmu.edu.vn

Ngày nhận bài: 6.7.2021

Ngày phản biện khoa học: 31.8.2021

Ngày duyệt bằi: 10.9.2021
Nguyễn Xuân Hậu ${ }^{1}$

phương pháp: Nghiên cứu mô tả trên 80 bệnh nhân đưỡc chẩn đoán vi ung thư tuyến giáp thể nhú, được phẩu thuật tại bệnh viện Đại học Y Hà Nội tữ tháng $3 / 2016$ đến tháng 1/2020. Kết quả: Tỉ lệ sờ thấy u trên lâm sàng là $39,8 \%$, u ở 1 thùy $93,7 \%$. hạch cổ trên lâm sàng 14,9. U trên siêu âm 100\%, u TIRADS 4 chiếm 77,6\%. Hạch trên siêu âm 25,5\%; hạch cổ bên $65,9 \%$, trong đó mất cấu trúc xoang hạch $68,3 \%$, vôi hóa trong hạch $31,7 \%$. FNA khối u $100 \%$, kết quả dương tính $77 \%$, nghi ngờ 18,3\%, âm tính 4,7\%. Kết luận: Vi ung thư tuyến giáp thể nhú chủ yếu phát hiện qua khám sức khỏe định kỳ, bệnh ít triệu chứng, 